\title{
Knowledge and perceptions of low-calorie sweeteners in an adult population
}

\author{
C. Logue, M. O’Mahony, E. Phair, H. Dougherty, C. McDaid and A.M. Gallagher \\ Northern Ireland Centre of Food and Health (NICHE), School of Biomedical Sciences, Ulster University, Coleraine, \\ Northern Ireland BT52 1SA
}

Low-calorie sweeteners (LCSs) are commonly used to provide a sweet taste that is comparable to sugars but with reduced energy and minimal effects on glycaemia ${ }^{(1,2)}$. As such, they have become increasingly prevalent in today's consumer market ${ }^{(3)}$ and are often used as a weight management tool ${ }^{(4)}$ or by individuals with diabetes mellitus ${ }^{(2)}$. Following a stringent safety assessment, an acceptable daily intake (ADI) is usually assigned for each LCS prior to approval for use ${ }^{(5)}$; however debate persists around the benefits and risks of LCS consumption. Dietitians' perceptions of LCSs were recently investigated revealing a diversity of attitudes ${ }^{(6)}$. However, limited scientific data are available on consumer attitudes towards LCSs and therefore the present study aimed to assess knowledge and perceptions of LCSs within an adult population.

A cross sectional study was conducted via the administration of an online survey comprising thirty-five questions designed to collect information on demographics, knowledge and perceptions of LCSs. The survey was disseminated among staff and students at the Ulster University by email and to a wider audience via social media sites. Statistical analysis, including Chi Square test, was conducted using SPSS to explore relationships between knowledge and perceptions of LCSs and $P<0.05$ was considered statistically significant.

A total of 741 individuals ( $282 \mathrm{M} ; 459 \mathrm{~F}$ ) completed the survey between March-July 2016. Of these, 73.5\% ( $n$ 545) reported being aware of LCSs; however, participants could identify average of 2.0 (SD; 1.9) LCSs from the list LCSs approved for use in Europe. Furthermore, the majority of participants $(89.2 \% ; n$ 661) reported being unaware of an ADI for LCSs. With regards to perceptions of LCSs, $34.3 \%(n=254)$ were of the opinion that LCS should not be used and $20.9 \%(n 155)$ were of the opinion that they should be used; the remainder $(44.8 \% ; n$ 332) declared no opinion on LCS use. Those who were 'aware of ADI' were more likely to have a positive perception of LCSs than those who were unaware or unsure of ADI (Fig. $1 ; P<0.001$ ).

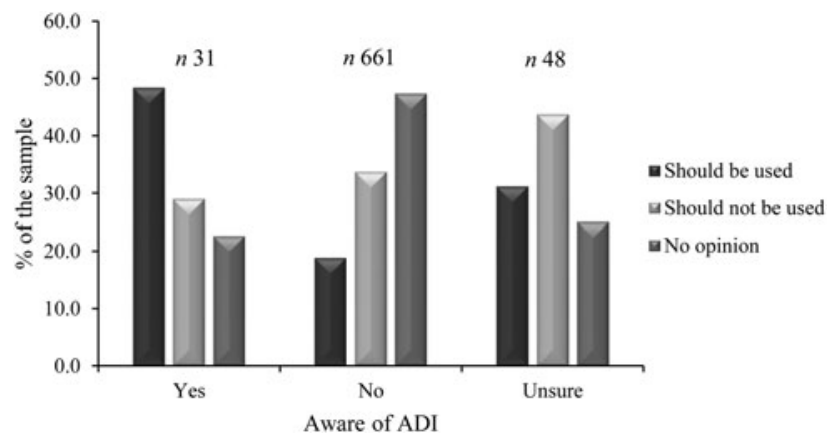

Fig. 1. Perceptions of LCS use by awareness of ADI.

A high level of awareness of LCSs was observed within this population; however there appeared to be a relative lack of awareness of specific LCSs, as well as an important regulatory aspect of LCSs i.e. ADI. This was associated with a more negative perception of LCSs suggesting that improved education around LCSs might improve acceptability within the general population.

1. Fernstrom J.D. (2015) Ann Rev Food Sci Technol 6, 119-136.

2. Wiebe N., Padwal R., Field C., et al. (2011) BMC Med 9, 123.

3. Zygler A., Wasik A. \& Namies'nik J (2009) Trends Anal Chem 28(9), 1082-1102.

4. Miller P.E. \& Perez V. (2014) Am J Clin Nutr 100(3), 765-777.

5. Logue C., Dowey L.C., Strain J.J. et al. (2016) Proc Nutr Soc 75(2), 216-225.

6. Harricharan M., Wills J., Metzger N., et al. (2014) Eur J Public Health 25(3), 472-476. 